\title{
The Music of Thinking
}

A Literary Experiment with the Great Themes of Philosophy Martin Seel

In his book Theorien (Frankfurt am Main: S. Fischer, 2009) Martin Seel presents a philosophical and literary experiment in which he desists from introducing a single grand theory in favour of offering a number of smaller theories. In an aphoristic manner these personal and poetic observations are linked to rigorous reflections on the classical themes of human selfunderstanding: happiness and morality, failure and beauty, sickness and death, sense and understanding, knowledge and freedom, religion and $\mathrm{mu}$ sic. Staying clear of disciplinary formations, the author shuffles the cards of epistemology, ethics and aesthetics in order to address philosophy as a whole without extinguishing its fire within the confines of a systematic edifice. This collection of shortcuts can be read from beginning to end, or backwards, or starting in the middle; as a reflection on thinking; a play with the voices of passion; a variation on foundations and pitfalls of action; a defence of the indeterminate in all that is determinate; as a fragment of a prosaic confession. These heterogeneous gestures unfold an improvised text that tracks the uncertainties of life and of writing. This text is an excerpt from the book, published in Die Zeit no. 37, September, 2009.

"My name is John Ford," the director is reported to have said at a meeting of the Directors Guild in Hollywood in October 1950, while speaking out against the supporters of Senator McCarthy, "I make Westerns." My name is M.S.; I make theories.

The word "theory" once stood for the ability to see everything in one thing and one thing in everything. However, if you cannot behold this one essence of everything (and there is quite some evidence that indeed none of us can), you may want to stick to multiplicity instead. This is what happens here: Various things are subjected to a closer look, including the gaze that regards them variously. Regarding - the world, our knowledge of it and our expectations for it - in this or that respect: There is nothing else for us to do. 
A cosmos can be found anywhere. I could never take my eyes off the barges on the Rhine, carrying everything with them, busy labourers and children at play, cargo compartments and storerooms, the bridge of the ship high above, a lower living area with curtains and geraniums, bicycles and sometimes a small car for trips on land, carried along by a steady movement within a flowing movement.

To stand at the edge of life and yet being surrounded by life on all sides in an empty compartment in a full train, in a quiet room in a flat full of boisterous children, being the last remaining guest at the end of a party, moving through the noise of the city - this is the position of utmost happiness and of utmost unhappiness as well. This happiness is the ultimate happiness, precisely because it holds the position of despair without being touched by it, and this despair is the ultimate despair, precisely because it holds the position of happiness without possessing it.

A little respite - that is all the happy as well as the unhappy can hope for.

Early in the morning, a man makes his way through these rooms carrying a plastic bag. He asks everyone for directions to the exit that he is not looking for; his shuffling feet are still heard in the evening. The person observing this is here for a few hours with his mother, who only recognises him from the photograph. However, she feels that he is close, right now at least, even if he has to bend down to look into her constantly reverted eyes. In her lighter moments, she cries, or laughs unexpectedly. Then she punches him on the shoulder, like a mother treating her adult son as though he were her little boy.

Being alone, you are free to follow your own rhythm. A lonely person, however, hears only his own heart, yearning for melodies based on another frequency.

Variation, especially in its more fluid plural form, is one of those beautiful words that actually demonstrate what they say. A-i-a-i-o: an alternation of sounds in which repetition combines with change. Philosophical activity follows a similar sequence. Thoughts are picked up, carried along for a while and then let go, but not unchanged. It animates them, it moves them, it resides in their motion.

We dispose neither of the world nor of ourselves. At the heart of all dis- 
posal, and only there, lies that which is beyond disposal. It is neither an attendant incident nor a mere phenomenon; it is a source of all effective action. The powers of fusion and diffusion meet where we have the power to think and act. Being determinant means being within the indeterminate. Determination is an act of limitation and is thus limited itself.

You can do many things either right or wrong, but not everything. "That's right," we say when someone's judgement is accurate. "That was wrong," we say when someone does something inappropriate. Right and wrong can be judgements and actions, plans and strategies, addresses and instructions - but not the course and consummation of a life. As soon as we make judgments about this, then right and wrong and related terms turn into comparatives. We succeed to a greater or smaller degree. The idea of a correct life is wrong. To know this you only need to have once stood, eyes open, between two women, two jobs, two cities, two friends, two children or two ill people. Believing in such simple cases that we have done everything right (chosen the best thing, not wasted or missed anything, not hurt anyone, not gone behind anyone's back) requires true blindness. There is no morality without regret - and no regretting that this is so.

There is an elegant chess move, transforming life's ups and downs into an avenue of unique accomplishments. All you have to do is affirm the glorious path of life instead of the volatile states of life, choose decisiveness instead of decisions, your own freedom instead of your own mistakes: I did it my way. Whatever happened was good, says the Sinatra doctrine, because it was my own original, underived way of doing things right and wrong. Morally, this doctrine is dubious; the greatest criminals would be happy to subscribe to it. But that does not make it wrong. It is the coolest source of happiness to be able to say that one's life - all told, and, above all, in spite of everything - it has been worth it. Even those who are not famous for their massacres can benefit from this happiness.

In every virtue dwells its opposite, in every vice dwells the seed of a virtue. Justice can be narrow-minded; prudence can be inertia, temperance can be wasteful and pity can be hurtful; care can be deadly; generosity can be careless, curiosity can be greedy. Greed can turn into receptiveness for the desired, carelessness into generosity, oppression into an embrace, sympathy into regret, extravagance into economy, inertia into perception, calculation into an encounter. 
Virtues are vices that do not act out their worst aspects; vices are virtues that neglect what is best in them.

Working on a world that is better for me means working for a better world so long as I am working on a reality that I share with many others. Yet it is often easier to combine the endeavour to create a better world for me - both on a small and a large scale - with endangering or destroying the well-being of others. Our moral sense re-directs our energies from destruction to protection. This re-direction is its meaning. Considered as work towards a perfect world, this would only be the spearhead of global destruction.

The little word "true" - which is a four-letter word in a number of languages - is worked into the jewellery of language like a small, sparkling diamond. It keeps our conclusions open, also when it confirms our opinion. It makes objections possible where we are certain we are right. Along with its assistant, the five-letter word "false," it tests the strength and sustainability of our views -and lets us fear that they will not stand the test. It prevents us from believing in the possession of truth. It keeps us moving towards a possible correction of our course. In the name of "truth," millions have been murdered; in the name of "true" and "false," we remember the victims of the idolatry of absolute truths.

The concept of the world is tied to its cognizability - Kant's trump card. It only trumps, however, if we do not assume another incognizable reality behind the cognizable one; if the phantasm of an ultimate knowledge is eradicated; if the disinterest of the world with regard to our knowledge of it is not forgotten; if we think of the world in such a way that the reality of action is included in its domain from the beginning. Thinking the world through our thinking and action is the only way to think the world without betraying our own thinking, i.e. the only way to think the world, since thinking itself is part of the world it strives to apprehend.

Trying to apprehend something in its being-such (Sosein) is futile. On the other hand, the attempt to grasp it in a - in more than one - being-such holds promise of great success. Despite rumours to the contrary, things have no essence. Or, if we want to be generous, we could say they do have an essence, and often more than one, but this depends on what we consider to be essential about them. 
Every drug - be it painkillers, alcohol, anabolic steroids, narcotics or philosophical systems - promises one thing: you will be on the safe side. Addiction begins when we begin to believe this, as soon as we wish, just once, or at least once a month, a week, in the evening, in the morning, every hour, and, ultimately, for all time, that nothing could threaten us anymore . Consumed in this way, these remedies, which indeed make life easier and less painful, have the opposite effect: they turn us into stone. And the only thing that awaits us on the safe side is death.

Even if we think of ourselves as not free, we think of ourselves as thinking and by virtue of this as free.

Every deliberation has two aims: the limited one - to clarify this and that - and the unlimited one - to make use of and maintain our own freedom: to be more sober, richer, wilder, more tender, quieter, louder, more reserved, more boldly determinable than other living beings. We do not think merely in order to gain better insight. Rather, we do so because we are thinking beings who rarely take pleasure in stasis. We need harmony and symmetry, return and repetition as much as any other beings, yet, without the variations, without the music of thought, we would simply atrophy, even if it only is elevator music occasionally interrupted by our free improvisations, by the song of the sirens and the sound of silence.

Reason, according to Hume, is the slave of the passions, and what else should it be? Its task is to keep us in a good mood: to put us to bed when we are tired, to wake us up when it is time to get up, to guide us when we are lost, to seduce us when we lose interest. It does not obey one passion, but many. This is what bestows it with power. Listening to the voices of desire means, not silencing them, but letting them communicate with each other, speeding up their dance at times, slowing them down at others, applying the brakes to the paralysing ones, preserving the old, caring for the new, calming the unruly, waking the sleeping, killing the killers. Being ruled by them is to rule over them. Divide et impera: this slave knows her trade just as well as any other potentate. This is why Plato said that reason is the sovereign of the passions, and what else should it be? But every conductor is powerless if the ensemble does not play along. If every member of the ensemble does not join in, then there can be no performance. Here, power is powerless and powerlessness is power. As the slave of passions, reason is the mediator, as the mediator it is the generator, as the generator it is the handmaid of forces that are not her own, yet 
without them it would be nothing, whereas these, without reason, would not be nothing, but would be fighting for a lost cause.

Even within the realm of nature, the separation of powers rules. Processual laws do not tell us how the hare runs, they only stipulate certain ways in which it cannot move. There are no laws for its flight across the field, although the whole process unfolds in strict accordance with such laws. In the actual course of things, the forces of nature are in conflict with each other. It is not settled what will happen, only what will not happen - the hare will not suddenly rise into the air, for instance. We should not confuse the great expanse of the real with the narrow confines of our own laboratory - regardless of how large it may be - within which the effects of individual factors can be isolated experimentally. Outside, force and counterforce rule with unbridled impulse. My desire to eat the first gooseberry in my garden disturbs its ripening, even if the berry does not feel disturbed, since in any case it cannot feel anything at all. Yet with or without feeling, the process of all living things, from plants to primates, unfolds in an at times dance-like, but most often deadly game of disturbance and avoidance. One effort is thwarted by another, constantly generating unpredictable changes. How could it be possible, then, to predict changes that are subjected to the additional impact of reasons and counter-reasons?

Thinking disturbs the course of things as it would have been if there had been no thinking.

We should not look for the indeterminate nature of the world in the wrong place. The freedom of our thinking and action is not constituted by some causal indetermination, but by the indeterminate nature of our determination by reasons. Since there is no circumvention of the comprehensibility of our thoughts and intentions that could somehow tell us where they lead without following their winding paths, and since all production of determination is equally a production of indetermination, the world of action remains, in significant respects, an also undetermined and indeterminate world. Culture is indeed this: finding the definite in the indefinite, thus creating a new indefiniteness, which leads to new definiteness, and so on - ad infinitum. The indefinite is the infinite.

Since its beginnings, philosophy has been fuelled by the ambition to transfer the content of myth to its own discourse, and in this regard 
philosophy's contempt for the sophistications of literature has not been all-encompassing. As such, from its very beginnings, philosophy has been agnostic: it does not believe that our self-understanding requires the exclusive language of revelation. In its endeavour to make its clientele receptive and sensitive to what really counts, it has always waged a kind of drum battle with religion from which music has often emerged as the unsuspected winner.

In some corners of the world you can buy tickets for ferries that let passengers travel back and forth as often as they please, before finally leaving the boat, no doubt to give them the opportunity to spend more money in the ship's café. Some people take advantage of this opportunity, lingering, alone or in company, for hours or days in the flow of passing time. Philosophy is that kind of a ticket. For a very reasonable price, it lets us stay where we are, but in a movement that takes us to the very place to which we must return, sooner or later.

(C) 2009 S. Fischer Verlag GmbH, Frankfurt am Main. Translation by Eileen Laurie 